\title{
Molecular Characterization of Carbapenemase- Producing Gram-negative Bacteria Isolated from Clinical Specimens in Baghdad, Iraq
}

\author{
Saad L. Hamed* (D) and Noor A. Hasoon \\ Mustansiriyah University, College of Science, Department of Biology, Baghdad, Iraq.
}

\begin{abstract}
The emergence and spread of carbapenem-resistant Gram-negative bacteria is a worldwide emerging public health threat responsible for large number of nosocomail infections. Metallo- $\beta$-lactamases including IMP, VIM, and NDM as well as carbapenem hydrolyzing class D $\beta$-lactamase (OXA-48 like) are the predominant types that confer resistance to Carbapenem group of antibiotics. The aim of this study was to identify the carbapenemase encoding genes among Gram negative bacteria isolates. 42 isolates were identified depending on routine morphological tests followed by species identification using the VITEK 2 system. The 16S rDNA gene sequence was used for confirmation of the detection of Enterobacteriaceae and Pseudomonas aeruginosa. Antimicrobial susceptibility testing was performed using VITEK 2 system. For phenotypic detection of carbapenemase activity, modified carbapenem inactivation method (mCIM) was performed. The carbapenemases encoding genes $\left(b / a_{{ }_{\mathrm{IMP}}}, b l a_{\mathrm{SPM}^{\prime}}, b / a_{\mathrm{VIM}}\right.$, $\left.b / a_{\mathrm{NDM}}, b l a_{\mathrm{KPC}}, b l a_{\mathrm{BI}}, b / a_{\mathrm{OX} A^{\prime}} b / a_{\mathrm{AIM}}, b / a_{\mathrm{SIM}}, b / a_{\mathrm{GIM}}, b / a_{\mathrm{DIM}}\right)$ were amplified by PCR and the amplified products were sequenced. Forty two Gram-negative bacteria isolates including 25 of $P$. aeruginosa $(59.5 \%)$ and 17 of Enterobacteriaceae family (40.4\%) were identified. According to PCR-based method results, carbapenemase gene $b / a_{\mathrm{OXA}}-48$ was detected in $31(73.8 \%)$ of isolates, $b / a_{\mathrm{VIM}}$ in $23(54.7 \%)$ and $b / a_{\mathrm{NDM}}$ in $2(4.76 \%)$ of isolates. Twelve (28.5\%) of isolates harbored a combination of $b / a_{\mathrm{OXA}}-48$ and $b / a_{\mathrm{vIM}},(2.4 \%)$ coexistence $b / a_{\mathrm{OXA}}-48$ and $b / a_{\mathrm{NDM}}$ gene and $(2.4 \%)$ of isolates harbored a $b / a_{\mathrm{OXA}}-48, b / a_{\mathrm{VIM}}$ and $b / a_{\mathrm{NDM}}$ genes. No other carbapenemase genes were identified. Based on the present study, it was concluded that the high prevalence was in bla ${ }_{\mathrm{OXA}}-48$ gene, followed by $b / a_{\mathrm{VIM}}$ gene among carbapenemase-producing Gram-negative bacteria isolates.
\end{abstract}

Keywords: Enterobacteriaceae Pseudomonas aeruginosa, Carbapenemases.

*Correspondence: dr.saad71@uomustansiriyah.edu.iq

(Received: 27 January 2019; accepted: 11 March 2019)

Citation: Saad L. Hamed and Noor A. Hasoon, Molecular Characterization of Carbapenemase-Producing Gram-negative Bacteria Isolated from Clinical Specimens in Baghdad, Iraq, J Pure App/ Microbiol., 2019; 13(2):1031-1040. doi: 10.22207/JPAM.13.2.41

(c) The Author(s) 2019. Open Access. This article is distributed under the terms of the Creative Commons Attribution 4.0 International License which permits unrestricted use, sharing, distribution, and reproduction in any medium, provided you give appropriate credit to the original author(s) and the source, provide a link to the Creative Commons license, and indicate if changes were made. 


\section{INTRODUCTION}

Gram-negative bacteria that produce Carbapenemase have been related to increased mortality and critical nosocomial outbreaks that represent the main challenge in both therapeutic and infection control ${ }^{1}$.

The concern of carbapenemase-producing Gram-negative bacteria that emerged currently is due to it is often related to the occurrence of multiple drug resistant isolates for which few choices of antimicrobials stay available ${ }^{2}$.

Carbapenems are $\beta$-lactam antibiotics that used most frequently as last resource antibiotics for treating of multidrug-resistant Gram negative bacilli-causing infections, since they have the wide spectrum of bactericidal action and their stability against most of the $\beta$-lactamases, including ESBLs ${ }^{3}$.

The increase of carbapenem resistance in these microorganisms is a major concern globally. The most common mechanism of resistance is the production of carbapenem-hydrolysing enzymes, carbapenemases that hydrolyse most $\beta$-lactams ${ }^{4}$.

These enzymes encoding by multiple genes of resistance, which is associated with different mobile genetic determinants, thus conferring resistance to various classes of antimicrobials, such as aminoglycosides, fluoro-quinolones, tetracyclines, trimethoprim, sulphonamides, and phenicols ${ }^{5}$.

The major public health threat is with transmissible carbapenemases, which can increase the rate of mortality and limit the choice of appropriate antibiotic therapy ${ }^{6}$. The transmissible enzymes can be acquired unpredictably by important nosocomial pathogens such as Pseudomonas aeruginosa, Acinetobacter baumannii and members of the family Enterobacteriaceae ${ }^{7}$.

The most serious form of carbapenem resistance is mediated by carbapenem-hydrolyzing $\beta$-lactamases, including metallo- $\beta$-lactamases (MBLs), such as imipenemase (IMP), Verona imipenemase (VIM), New Delhi metallo- $\beta$ lactamase (NDM), Ambler class A Klebsiella pneumoniae carbapenemase (KPC), and class $D$ oxacillinase-48 (OXA-48) ${ }^{8}$.

Because of the lack of implementing standardized protocols for detection of carbapenemase-producing isolates in many countries that probable to be the major reservoirs, the actual prevalence of these producers is still unknown. It is estimated that we are on the rim of a global epidemic with carbapenemase-producing isolates, which in the hospital environment is likely to be caused mostly by all types of nosocomial carbapenemase-producers (e.g. KPC, IMP, VIM, NDM and OXA-48) ${ }^{9}$.

In Iraq, we showed that a significant increase in carbapenem-resistant bacteria in the last two decades, especially after the 2003 War, maybe is due to the Iraq's openness to the world and the entry of foreign workers, especially from the endemic area from the Indian subcontinent like Bangladesh and other countries.

For all of the mentioned above, as well as, few report investigated the molecular basis of resistance to carbapenems among Gram-negative bacteria, this study aimed to identify the genes which is responsible for encoding carbapenemase enzymes in these organisms.

\section{MATERIALS AND METHODS \\ Bacterial isolates}

A total of 42 different Gram-negative isolates were collected from various patient specimens from different hospitals in Baghdad city, Iraq during a period between October 2017 and February 2018. The isolates were identified initially depending on morphological characteristics as described previously ${ }^{10}$, followed by identification by using VITEK ${ }^{\circledast} 2$ compact system (bioMeriux, France). Genotypic method was used to confirm the identification of isolates at species level using 16S rDNA gene sequences.

\section{Antimicrobial susceptibility test}

Antimicrobial susceptibility test was performed with the VITEK 2 system (bioMe'rieux, France) using AST 69 card as described by the manufacturer. The tested antibiotics were: Ampicillin, Amoxicillin/Clavulanic Acid, Ampicillin / Sulbactam, Cefazolin, Ceftazidime, Ceftriaxone, Cefepime, Ciprofloxacin, Levofloxacin, Imipenem, Amikacin, Gentamicin, Trimethoprim/ Sulfamethoxazole and Nitro-furantoin.

Phenotypic detection of carbapenemase production

The modified carbapenem inactivation 
method (mCIM) was performed according to CLSI guidelines ${ }^{11}$. In briefly, using sterile inoculating loop, $1 \mu$ l of test organism was suspended in $2 \mathrm{ml}$ of tryptic soy broth, the bacterial suspension was homogenized by vortex. Then, a $10-\mu \mathrm{g}$ meropenem disk was immersed into the suspension. Subsequently, the culture was incubated for 4 hours at $35^{\circ} \mathrm{C}$, prepared $0.5 \mathrm{McF}$ arland suspension of $E$. coli $\mathrm{ATCC}^{\circledR}$ 25922(a carbapenem-susceptible strain) that was inoculated on Muellar-Hinton agar(MHA) plates streaked as cell lawn.

After the incubation, the disk was removed using a $10-\mu l$ inoculating loop; the loop was dragged along the edge of the tube during removal to remove excess liquid, and the disk was placed onto the inoculated MHA plate, which was then incubated in for 18-24 hours at $35^{\circ} \mathrm{C}$. Following the incubation, diameter of the inhibition zone around the disc was measured, a zone diameter of 6-10 $\mathrm{mm}$ or presence of colonies within a 16-18 $\mathrm{mm}$ zone was considered to be a positive result, 16-18 $\mathrm{mm}$ an indeterminate result, and $19 \mathrm{~mm}$ a negative result.

Genotypic identification of carbapenemaseencoding genes

DNA isolation of bacteria

Pure culture of bacterial isolates were grown overnight in liquid nutrient broth medium (NB) for the isolation of genomic DNA using the Genomic DNA purification kit (Promega, USA) according to the manufacturers protocol.

All isolates were subjected to molecular screening to detect carbapenemase-encoding genes by using PCR amplification technique. In this study, multiplex PCR was used to detect carbapenemase encoding genes from clinical isolates and the PCR products were sequenced.

\section{Multiplex PCR}

Eleven pairs of primers (Alpha DNA, Canada) were used in this method, that defined into 3 multiplex reaction. No.1 included detection of bla ${ }_{\mathrm{IMP}}, b / a_{\mathrm{SPM}}$ and $b / a_{\mathrm{VIM}}$ genes, No.2 included detection of bla $a_{\mathrm{NDM}}, b / a_{\mathrm{KPC}}, b / a_{\mathrm{BIC}}$ and $b / a_{\mathrm{OXA}}$ genes and No. 3 included detection of $b / a_{\mathrm{AIM}^{\prime}}, b / a_{\mathrm{SIM}^{\prime}} b / a_{\mathrm{GIM}}$ and bla ${ }_{\mathrm{DIM}}$ genes.

Different primers (Table 2) were used, the PCR reaction mixture contained: $2 \mu$ l of template DNA, $12.5 \mu$ l of Go Taq Green Master Mix (2x) (Promega (USA), $1 \mu$ l from each of the following primers : IMP, SPM ,VIM, NDM, BIC, KPC or OXA and the volume was completed to $25 \mu$ l with nuclease free water. While the reaction mixture of $25 \mu \mathrm{l}$ for each of the following primers: AIM, SIM, GIM or DIM composed from $2 \mu$ l of template DNA,12.5 $\mu \mathrm{l}$ of Go Taq Green Master Mix, $1 \mu$ l of each primers and $1.5 \mu$ l of dimethyl sulfoxide (DMSO) and the volume was completed to $25 \mu \mathrm{l}$ with nuclease free water ${ }^{12}$. Cycle conditions were as followed: $10 \mathrm{~min}$ at $94^{\circ} \mathrm{C}$ and 36 cycles of amplification consisting of $30 \mathrm{sec}$ at $94^{\circ} \mathrm{C}, 40 \mathrm{sec}$ at $52^{\circ} \mathrm{C}$ and $50 \mathrm{sec}$ at $72^{\circ} \mathrm{C}$, with $5 \mathrm{~min}$ at $72^{\circ} \mathrm{C}$ for the final extension.

The amplified products were electrophoresed in 2\% agarose gel in 1x TBE buffer containing red safe dye at $100 \mathrm{~V}$ for 50 minutes. Then, the PCR products were visualized under UV light by UV transilluminator. The E.coli ATCC 25922 strain was used as negative control.

\section{Sequencing of PCR products}

The amplified PCR products were sequenced at Macrogen DNA sequencing Company (Seoul, Korea). DNA sequences were analyzed and compared with standard strain using BLAST (Basic Local Alignment Search Tool) in National Center for Biotechnology Information website (http://www. ncbi.nlm.nih.gov/ BLAST).

\section{Genebank accession numbers}

The 165 rDNA gene, bla $a_{\mathrm{VIM}}-2$ gene, $b / a_{\mathrm{OXA}}-48$ gene and $b / a_{\mathrm{NDM}}$ gene sequences from this study were deposited in Genbank database under accession numbers MK182251 to MK182258, MK156197 to MK156202 and MK159338 to MK159352.

\section{RESULTS}

Forty two clinical isolates of Gramnegative bacteria (Pseudomonas aeruginosa and members of Enterobacteriaceae family) were isolated from 32 patients including: 40 (95.2\%) isolates from burns and $2(4.76 \%)$ isolates from urine infection were collected. From 42 isolates, 25(59\%) were $P$. aeruginosa and $17(40 \%)$ were Enterobacteriaceae (six of Klebsiella pneumoniae, seven of E. coli and four of Enterobacter cloacae) (Table 2).

The patterns of antimicrobial resistance were as followed: (100\%) to ampicillin and cefazolin and Ceftriaxone, (95.2\%) to ampicillin/ sulbactam and imipenem, (92.8\%) to amoxicillin/ clavulanic acid and trimethoprim/sulfamethoxazol, $(85.71 \%)$ to cefepime, $(80.95 \%)$ to 
ceftazidime and gentamicin, (76.1\%) to amikacin, (69.04\%) to ciprofloxacin, $(66.6 \%)$ to levofloxacin and (64.28\%) to nitrofurantoin (Fig. 1).
For $\mathrm{mCIM}$, all isolates showed positive results (25 isolates of Pseudomonas aeruginosa and 17 isolates of Enterobacteriaceae family)

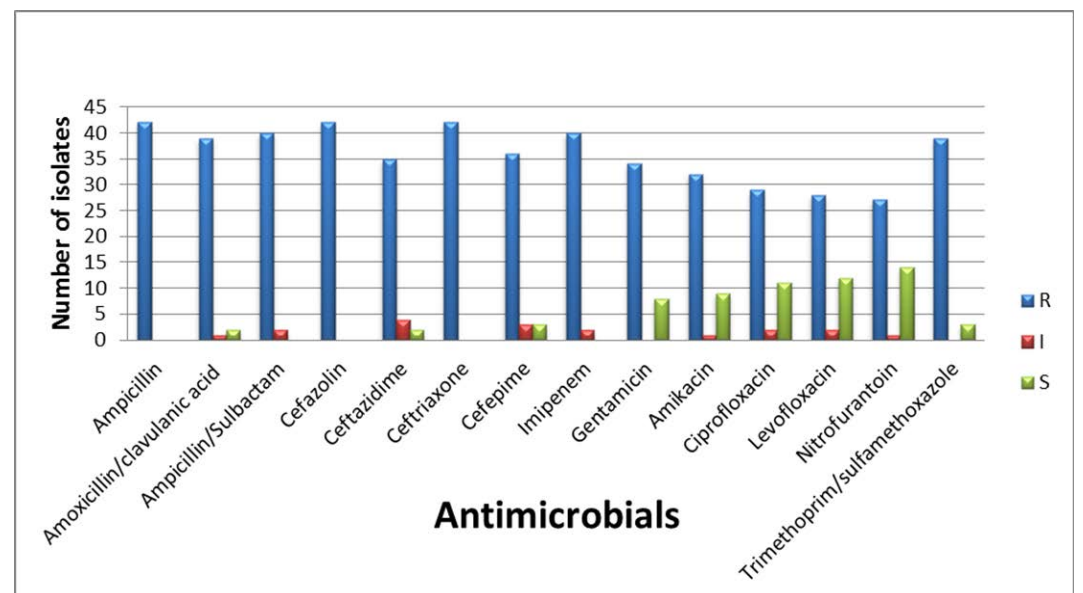

Fig. 1. The Antibiogram pattern of isolates towards antimicrobials used in this study. (R): Resistant, (I): Intermediate and (S): Susceptible.

Table 1. The primers used in this study

\begin{tabular}{|c|c|c|c|c|}
\hline Gene & Primer & Sequence $\left(5^{\prime}-3^{\prime}\right)$ & $\begin{array}{l}\text { Product } \\
\text { size (bp) }\end{array}$ & Reference \\
\hline \multirow[t]{2}{*}{ PASS } & PA-SS-F & GGGGGATCTTCGGACCTCA & 956 & 13 \\
\hline & PA-SS-R & TCCTTAGAGTGCCCACCCG & & \\
\hline \multirow[t]{2}{*}{ 16SrRNA } & $27 \mathrm{~F}$ & AGAGTTTGATCCTGGCTCAG & 930 & 14 \\
\hline & $1492 \mathrm{R}$ & CTTGTGCGGGCCCCCGTCAATTC & & \\
\hline \multirow{2}{*}{$b / a_{\mathrm{IMP}}$} & IMP-F & GGAATAGAGTGGCTTAAYTCTC & 232 & 12 \\
\hline & IMP-R & GGTTTAAYAAAACAACCACC & & \\
\hline \multirow[t]{2}{*}{$b / a_{\mathrm{SPM}}$} & SPM-F & AAAATCTGGGTACGCAAACG & 271 & \\
\hline & SPM-R & ACATTATCCGCTGGAACAGG & & \\
\hline \multirow{2}{*}{$b / a_{\mathrm{AIM}}$} & AIM-F & CTGAAGGTGTACGGAAACAC & 322 & \\
\hline & AIM-R & GTTCGGCCACCTCGAATTG & & \\
\hline \multirow[t]{2}{*}{$b / a_{\mathrm{VIM}}$} & VIM-F & GATGGTGTTTGGTCGCATA & 390 & \\
\hline & VIM-R & CGAATGCGCAGCACCAG & & \\
\hline \multirow{2}{*}{$b / a_{\mathrm{OXA}}$} & OXA-F & GCGTGGTTAAGGATGAACAC & 438 & \\
\hline & OXA-R & CATCAAGTTCAACCCAACCG & & \\
\hline \multirow[t]{2}{*}{$b l a_{\mathrm{GIM}}$} & GIM-F & TCGACACACCTTGGTCTGAA & 477 & \\
\hline & GIM-R & AACTTCCAACTTTGCCATGC & & \\
\hline \multirow[t]{2}{*}{$b / a_{\mathrm{BIC}}$} & BIC-F & TATGCAGCTCCTTTAAGGGC & 537 & \\
\hline & BIC-R & TCATTGGCGGTGCCGTACAC & & \\
\hline \multirow[t]{2}{*}{$b / a_{\mathrm{SIM}}$} & SIM-F & TACAAGGGATTCGGCATCG & 570 & \\
\hline & SIM-R & TAATGGCCTGTTCCCATGTG & & \\
\hline \multirow[t]{2}{*}{$b / a_{\mathrm{NDM}}$} & NDM-F & GGTTTGGCGATCTGGTTTTC & 621 & \\
\hline & NDM-R & CGGAATGGCTCATCACGATC & & \\
\hline \multirow[t]{2}{*}{$b / a_{\mathrm{DIM}}$} & DIM-F & GCTTGTCTTCGCTTGCTAACG & 699 & \\
\hline & DIM-R & CGTTCGGCTGGATTGATTTG & & \\
\hline \multirow[t]{2}{*}{$b / a_{\mathrm{KPC}}$} & KPC-Fm & CGTCTAGTTCTGCTGTCTTG & 798 & \\
\hline & $\mathrm{KPC}-\mathrm{Rm}$ & CTTGTCATCCTTGTTAGGCG & & \\
\hline \multirow[t]{2}{*}{ Pre NDM } & pre-NDM-F & CACCTCATGTTTGAATTCGCC & 984 & 15 \\
\hline & pre- NDM-R & СTCTGTCACATCGAAATCGC & & \\
\hline
\end{tabular}


indicating the production of carbapenemase by these strains. Molecular tests confirmed that at least one carbapenemase gene in all isolates that were phenotypically carbapenemase positive, with the exception of one Pseudomonas aeruginosa isolate was carbapenemase-positive by phenotypic test despite being negative for the detection of carbapenemase encoding genes.

Multiplex PCR-based methods were conducted to detect the carbapenem-resistant

Table 2. Distribution of carbapenemases encoding genes among isolates

\begin{tabular}{|c|c|c|c|}
\hline $\begin{array}{l}\text { Isolates } \\
\text { No. }\end{array}$ & Bacterial species & Genes & $\begin{array}{l}\text { Isolation } \\
\text { source }\end{array}$ \\
\hline SN1 & Escherichia coli & blaVIM & Burn \\
\hline SN2 & Enterobacter cloacae & blaVIM & Burn \\
\hline SN3 & Pseudomonas aeruginosa & blaVIM & Burn \\
\hline SN4 & Escherichia coli & blaVIM & Burn \\
\hline SN5 & Pseudomonas aeruginosa & blaVIM\& blaOXA-48 & Burn \\
\hline SN6 & Pseudomonas aeruginosa & blaVIM\& blaOXA-48 & Burn \\
\hline SN7 & Pseudomonas aeruginosa & $\begin{array}{l}\text { blaVIM\& blaNDM\& } \\
\text { blaOXA-48 }\end{array}$ & Burn \\
\hline SN8 & Pseudomonas aeruginosa & blaVIM\& blaOXA-48 & Burn \\
\hline SN9 & Pseudomonas aeruginosa & blaVIM & Burn \\
\hline SN10 & Pseudomonas aeruginosa & blaNDM\& blaOXA-48 & Burn \\
\hline SN11 & Pseudomonas aeruginosa & blaVIM\& blaOXA-48 & Burn \\
\hline SN12 & Pseudomonas aeruginosa & blaOXA-48 & Burn \\
\hline SN13 & Pseudomonas aeruginosa & blaVIM & Burn \\
\hline SN14 & Pseudomonas aeruginosa & blaVIM & Burn \\
\hline SN15 & Pseudomonas aeruginosa & blaVIM\& blaOXA-48 & Burn \\
\hline SN16 & Escherichia coli & blaVIM & Burn \\
\hline SN17 & Pseudomonas aeruginosa & blaOXA-48 & Burn \\
\hline SN18 & Enterobacter cloacae & blaVIM \& blaOXA-48 & Burn \\
\hline SN19 & Pseudomonas aeruginosa & blaOXA-48 & Burn \\
\hline SN20 & Pseudomonas aeruginosa & blaOXA-48 & Burn \\
\hline SN21 & Pseudomonas aeruginosa & blaVIM & Burn \\
\hline SN22 & Pseudomonas aeruginosa & None & Burn \\
\hline SN23 & Pseudomonas aeruginosa & blaOXA-48 & Burn \\
\hline SN24 & Pseudomonas aeruginosa & blaOXA-48 & Burn \\
\hline SN25 & Pseudomonas aeruginosa & blaOXA-48 & Burn \\
\hline SN26 & Escherichia coli & blaOXA-48 & Burn \\
\hline SN27 & Escherichia coli & blaVIM\& blaOXA-48 & Burn \\
\hline SN28 & Klebsiella pneumoniae & blaOXA-48 & Burn \\
\hline SN29 & Pseudomonas aeruginosa & blaOXA-48 & Burn \\
\hline SN30 & Escherichia coli & blaVIM & urine \\
\hline SN31 & Klebsiella pneumoniae & blaOXA-48 & Burn \\
\hline SN32 & Enterobacter cloacae & blaOXA-48 & Burn \\
\hline SN33 & Pseudomonas aeruginosa & blaVIM\& blaOXA-48 & Burn \\
\hline SN34 & Enterobacter cloacae & blaOXA-48 & urine \\
\hline SN35 & Klebsiella pneumoniae & blaVIM\& blaOXA-48 & Burn \\
\hline SN36 & Klebsiella pneumoniae & blaOXA-48 & Burn \\
\hline SN37 & Pseudomonas aeruginosa & blaOXA-48 & Burn \\
\hline SN38 & Klebsiella pneumoniae & blaOXA-48 & Burn \\
\hline SN39 & Pseudomonas aeruginosa & blaVIM\&blaOXA-48 & Burn \\
\hline SN40 & Klebsiella pneumoniae & blaVIM\&blaOXA-48 & Burn \\
\hline SN41 & Escherichia coli & blaOXA-48 & Burn \\
\hline SN41 & Pseudomonas aeruginosa & blaVIM \& blaOXA-48 & Burn \\
\hline
\end{tabular}


genes. The most prevalent carbapenemase gene bla ${ }_{\mathrm{OXA}}-48$ was found in $31(73.8 \%)$ of the 42 isolates, followed by $b / a_{\mathrm{vIM}}$ gene that was detected in 23 $(54.7 \%)$ and $b / a_{\mathrm{NDM}}$ gene in $2(4.76 \%)$. The results showed the presence of bla $a_{\text {OXA }}-48$ gene were found in $19(45.2 \%)$ of $P$. aeruginosa, $6(14.2 \%)$ of K.pneumoniae, $3(7.1 \%)$ of E.coli isolates and in $3(7.1 \%)$ of E. cloacae; bla ${ }_{\mathrm{vIM}}$ gene in $14(33.3 \%)$ of P.aeruginosa isolates, $2(4.7 \%)$ of $K$.pneumoniae isolates, $5(11.9 \%)$ of E.coli isolates and $2(4.7 \%)$ of E. cloacae isolates and presence of $b / a_{\mathrm{NDM}}$ gene in $2(4.76 \%)$ of P.aeruginosa (Table 1). On the other hand, bla ${ }_{\mathrm{IMP}}, b l a_{\mathrm{SPM}^{\prime}} b l a_{\mathrm{KP} C^{\prime}}$ bla $a_{\mathrm{BI},}$ bla $a_{\mathrm{AIM}^{\prime}} b / a_{\mathrm{SIM}^{\prime}}$ bla $a_{\mathrm{GIM}}$ and bla ${ }_{\text {DIM }}$ genes were not detected in all isolates. Interestingly, twelve isolates (28.5\%) harbored a combination of blaOXA-48 and bla ${ }_{\mathrm{VIM}}$, one isolate $(2.4 \%)$ co-harboring three carbapenemase-encoding genes $b / a_{\mathrm{OXA}}-48$ and bla $a_{\mathrm{NDM}}$ gene and $1(2.4 \%)$ harboring bla $a_{\mathrm{OXA}}-48, b / a_{\mathrm{VIM}}$ and $b / a_{\mathrm{NDM}}$ genes.

\section{DISCUSSION}

Carbapenemase-producing bacteria have become a major problem worldwide, which has emerged due to the increased dependence on carbapenems as a last resource to treat bacteria with multidrug-resistant ${ }^{16}$.

Carbapenemases represent the stringent threat for global human health and stand as one of the most challenging issues facing infectious disease containment in the subsequent years ${ }^{17}$.

Notwithstanding the small number of isolates, the author found the dominant OXA-48 carbapenemases among studied isolates.

The most current and concern development is the rapid rise in emerging and dissemination of OXA-48, particularly in $K$. pneumoniae. In 2001, the OXA-48-producing Enterobacteriaceae was first identified in Turkey, then later reported in various countries including the Middle East, North Africa, and Europe ${ }^{18}$. In a local study carried by Abdulla et al. (2016), they reported that the bla $a_{\text {OXA-48 }}$ genes were detected in $25 \%$, of the E.coli isolates and $21.4 \%$ in $K$. pneumoniae isolates ${ }^{19}$.

Several studies in regional countries reported the predominance of bla ${ }_{\mathrm{OXA}}-48$ among Gram negative bacteria, as it was $49 \%$ in Arabian Gulf ${ }^{20}, 53.3 \%$ in the $\mathrm{UAE}^{21}, 88 \%$ in Lebanon ${ }^{22}$, $49.2 \%$ in Egypt ${ }^{16}$ and $86 \%$ in Turkey ${ }^{8}$, on the other hand, a study by Mohamed et al., reported decrease in the rate $(22.4 \%)$ of this gene in P.aeruginosa isolates ${ }^{23}$.

The increasing incidence of blaOXA- 48 has been described in varying worldwide countries, in France, bla oxA -48 gene represented $76.8 \%$ of carbapenemase producing $K$. pneumoniae, $81.1 \%$ of carbapenemase- producing E.coli, $75.8 \%$ of carbapenemase-producing Enterobacter spp. ${ }^{24}$, in Romania, $80 \%$ of K.pneumonie isolates harbored a bla $_{\text {oxA }}-48$ gene $^{25}$, while in Canada, Mataseje et al., reported that bla ${ }_{\mathrm{OXA}}-48$ found in $31.3 \%$ of isolates 26 .

In regard to existence of the bla ${ }_{\mathrm{VIM}}$ gene, the results also showed increasing in prevalence rate, as it was $54.7 \%$ of carbapenem-resistant isolates have possessed this gene.

A local study done by Al-Jubori et al, (2016) showed that the prevalence rate of $b / a_{\mathrm{VIM}}$ gene was $25 \%$ in $A$. baumannii ${ }^{27}$, while another study done by Hammadi et al .(2015), reported that all E.coli isolates did not carry bla ${ }_{\mathrm{VIM}}$ gene ${ }^{28}$.

The VIM types are the most frequent among class $B$ carbapenemases which have been detected in all continents ${ }^{29}$. VIM enzymes were firstly reported in isolates of $P$. aeruginosa, and then emerged in Enterobacteriaceae as well. Subsequently in a number of regional countries, a study carried out in Saudi Arabia describing that P.aeruginosa strain harboring the $b / a_{\mathrm{VIM}}-2$ gene from a Saudi patient hospitalized in France ${ }^{30}$.

In Iran, Rajabnia et al. (2015), reported that the $b / a_{\mathrm{VIM}}-1$ gene are presence in $30 \%$ of $K$. pneumoniae isolates ${ }^{31}$, while in Turkey, Haciseyitoglu et al. (2017) found that the percentage rate of this gene was low when it reached only $10 \%$ in E.cloacae ${ }^{32}$.

Hammami et al. (2011) revealed that the percentage of $b / a_{\mathrm{VIM}}-2$ gene was $67 \%$ in Tunisia ${ }^{33}$.

In Romania, Mereuta et al. (2013), showed that $48 \%$ of P.aeruginosa isolates carried $a_{b l a}{ }_{\mathrm{VIM}}-2$ gene $^{34}$, while in Korea, Hong et al. showed that $69 \%$ of isolates harbored the $b / a_{\mathrm{VIM}}-2$ gene ${ }^{35}$, on the other hand, Touati et al. (2013) mentioned that the percentage rate was $82 \%$ of the studied isolates ${ }^{36}$.

Since the detection of NDM-1 is firstly reported in India, there has been a global rise in the dissemination of NDM-1 carrying organisms. At first, the existence of NDM-1 was predominantly 
reported in Enterobacteriaceae, but reports occurring recently pointed out to its spread in Acinetobacter spp. and Pseudomonas spp. as well ${ }^{37}$.

The author found that bla ${ }_{\mathrm{NDM}}$ gene is presence in two isolates (4.7\%) of P.aeruginosa among carbapenem resistant isolates.

In local studies, Al-shara et al.(2014) reported that out of 36 carbapenem resistant P.aeruginosa isolates, only $5.6 \%$ of isolates harbored $b / a_{\mathrm{NDM}}$ gene ${ }^{38}$, another study by ALHarmoosh (2015) showed that the prevalence rate of bla ${ }_{\mathrm{NDM}}-1$ gene was $20 \%^{39}$, while in recent study by Hussein (2017), revealed that bla ${ }_{\mathrm{NDM}}-1$ gene was $40 \%$ in E.coli isolates ${ }^{40}$, however Hammoudi et al. showed that the percentage of the prevalence of bla $_{\mathrm{NDM}}-1$ gene was $100 \%$ in isolates ${ }^{41}$.

Bacterial isolates that produce NDM-1 enzyme may express numerous other unrelated resistance genes, such as OXA-48 type and VIM type that encode other carbapenemases, AmpC, extended-spectrum beta-lactamases, and other classes of antimicrobials ${ }^{42}$.

The prevalence of NDM-1 producing isolates were reported from different countries including the Gulf Corporation Council (GCC) which investigated in a total of 200 isolates collected from 16 hospitals in Saudi Arabia, Kuwait, Oman and the United Arab Emirates. Overall, NDM-1 was the most common encountered carbapenemase gene $46.5 \%{ }^{43}, 47.6 \%$ in Egypt $^{16}, 29.5 \%$ in Turkey ${ }^{8}$ and $7.8 \%$ in Tunisia ${ }^{44}$.

In Bangladesh, Khatun et al. (2015), reported the rate $73.7 \%$ of $b / a_{\mathrm{NDM}^{-1}}-{ }^{45}$, in Romania a study done by Dortet et al.(2015), revealed that 15 carbapenemase producing Enterobacteriaceae, were recovered from patients hospitalized between 2011 and 2013, 60\% harbored a bla ${ }_{\mathrm{NDM}}{ }^{-1}$ gene $^{25}, 100 \%$ in Russia ${ }^{46}$, as well as Dort et al. (2013) reported that the percentage of $b / a_{\mathrm{NDM}^{-1}}$ gene was $7.9 \%$ in France $^{24}$.

The global emergence of doubleand multi-carbapenemase-producing hospitalacquired Gram-negative pathogens, are mostly Klebsiella pneumoniae, Pseudomonas aeruginosa, and Acinetobacter baumannii ${ }^{47}$.

In Kuwait, Jamal et al. reported that two of the bla $a_{\mathrm{NDM}}$-1-producing isolates co-harbored bla $_{\mathrm{OXA}}-48$ carbapenemase $^{48}, 22.1 \%$ in Dubai ${ }^{21}, 4.5 \%$ in Turkey ${ }^{32}$ and $92.1 \%$ in Tunis ${ }^{44}$, while in India, kaziet al.(2014) revealed that $3.6 \%$ of the isolates possessed dual carbapene-masebla $a_{\mathrm{NDM}}$ and $b / a_{\mathrm{VIM}}$ genes $^{37}$.

A K. pneumoniae co-producing NDM-1 and OXA-232 (an OXA-48 variant) was imported to the USA from India ${ }^{49}$, and another was found also in a French hospital ${ }^{50}$, where its cross-transmission was documented ${ }^{47}$.

The ratio of carbapenemase producing isolates differs by geographic region, type of infection, specimen source, and selective pressure due to antibiotics. This difference also associated with variation among the different patients studied and the different rates of antibiotic used in different hospitals ${ }^{51}$.

The diversity of carbapenemases depends on the country; may be affected by historical and cultural relationships ${ }^{17}$. In our country, the wars, medical tourism, and Cross border transfer of patients particularly incoming workers might play a significant role in emerging and dissemination of different variants of carbapenemase encoding genes. There is an urgent need to find guidelines and appropriate procedures of infection control in order to deny such infections among patients.

\section{ACKNOWLEDGMENTS}

The authors thanks Mustansiriyah University (http://uomustansiriyah.edu.iq/) for its support during the tenure of this work.

\section{CONFLICT OF INTEREST}

The authors declare that there is no conflict of interest.

\section{AUTHORS' CONTRIBUTION}

$\mathrm{SH}$ designed the experiments and analyzed the data. $\mathrm{NH}$ performed the experiments and wrote the manuscript. SH read and approved the manuscript.

\section{FUNDING}

None.

\section{DATA AVAILABILITY}

The datasets of $16 \mathrm{~S}$ rDNA gene, blaVIM-2 gene, blaOXA-48 gene and blaNDM gene 
sequences from this study were deposited in NCBI database under accession numbers MK182251 to MK182258, MK156197 to MK156202 and MK159338 to MK159352. All relevant data are available from the authors upon request.

\section{ETHICS STATEMENT}

This article does not contain any studies with human participants or animals performed by any of the authors.

\section{REFERENCES}

1. Patel G., Robert A. Bonomo. Status report on carbapenemases: challenges and prospects. Expert Rev Antilnfect Ther, 2011; 9(5): 555-570.

2. Poirel L., Johann D. Pitout, Patrice N. Carbapene-mases: molecular diversity and clinical consequences. Future Microbiol.,2007; 2: 501-512.

3. Dos Santos G.S., E.G. Solidonio, M.C.V.V. Costa, ROAMelo, I.F.A.C. Souza, GRSilva, K.X.F.R. Sena. Study of the Enterobacteriaceae group CESP (Citrobacter, Enterobacter, Serratia, Providencia, Morganella and Hafnia): a review,"in The Battle Against Microbial Pathogens: Basic Science, Technological Advances and Educational Programs, ed A. M'ndez-Vilas (Badajoz: Formatex),2015; 2: 794-805.

4. Tarashi S., Hossein G., Soroor E., Ali P., Ali H. Phenotypic and molecular detection of Metallo-beta-lactamase genes among imipenem resistant Pseudomonas aeruginosa and Acinetobacter baumannii strains isolated from patients with burn injuries. Arch. Clin. Infect. Dis., 2016; 11(4): 1-6.

5. Nordmann P. Carbapenemase-producing Enterobacteriaceae: overview of a major public health challenge. M'd. Mal. Infect., 2014; 44: 51-56.

6. Bush K., Megan P., John L. Lock, Anne MQueenan, James HJorgensen, Ryan MLee, James SLewis, Deidre J. Detection systems for carbapenemase gene identification should include the SME serine carbapenemase. Intern. J. Antimicrob. Agents, 2013; 41(1): 1-4.

7. Thomson K.S. Extended-spectrum- $\beta$-lactamase, AmpC, and carbapenemase issues. J. Clin. Microbiol., 2010; 48(4): 1019-1025.

8. Iraz M., Azer" D zg n, Cemal S., Mehmet Z. Doymaz, Yasemin Akkoyunlu, Ayseg I S., Anton Y. Peleg, Osman B. "zg m s, FatihSBeris, Hakan K., Ayseg linek. Distribution of $\beta$-lactamase genes among carbapenemresistant Klebsiella-pneumoniae strains isolated from patients in Turkey. Ann. Lab. Med., 2015; 35(6): 595601.

9. Nordmann P., Thierry N., Laurent P. Global spread of carbapenemase-producing Enterobacteri-aceae. Emer Infect Dis., 2011; 17(10): 1791.

10. Atlas R. M., Parks L.C., Brown A.E. 1995. Laboratory manual of experimental microbiology. Mosby-Year Book Inc.

11. Clinical and laboratory standards institute. 2016. Performance standards for antimicrobial susceptibility testing. $26^{\text {th }}$ Edition. Supplement M100S. CLSI, Wayne, PA.

12. Poirel L., Timothy R. Walsh, Vincent C., Patrice N. Multiplex PCR for detection of acquired carbapenemase genes. Diag. Microbiol. Infect. Dis., 2011; 70(1): 119123.

13. Spilker T., Tom C., Peter V., John J. LiPuma. PCR-based assay for differentiation of Pseudomonas aeruginosa from other Pseudomonas species recovered from cystic fibrosis patients. J. Clin. microbiol, 2004; 42(5): 2074-2079

14. Magray M.S.U.D., Anup K., Anil K. Rawat, Shipra S. Identification of Escherichia coli through analysis of $16 \mathrm{~S}$ rRNA and 16S-23S rRNA internal transcribed spacer region sequences. Bioinformation, 2011; 6(10): 370-371.

15. Bonnin R.A., Thierry N., Laurent P., Patrice N. Phenotypical-, biochemical-and molecular-based techniques for detection of metallo- $\beta$-lactamase NDM in Acinetobacter baumannii. J. Clin. Microbio., 2012; 50(4)1419-1421.

16. Khalifa H.O., Ahmed M. Soliman, Ashraf M. Ahmed, Toshi S., Toshinori H., Mitsuyasul, YutaK, Shizuo K., Motoyuki S., Tadashi Tadashi S. High carbapenem resistance in clinical gram-negative pathogens isolated in Egypt. Microb. Drug Resist., 2017; 23(7): 838-844.

17. Leylabadlo H.E., Mohammad A., Mohammad A. Dissemination of carbapenemases producing Gram negative bacteria in the Middle East. Iran J. Microbiol, 2015; 7(5): 226

18. Adler A., Maya S., Mitchell J. Schwaber, Shiri N.-V., Yacoub D., Rotem E., Ester S., Shmuel B., Samira M., Yehuda C. Introduction of OXA-48-producing Enterobacteriaceae to Israeli hospitals by medical tourism. J. antimicrob. chemother, 2011; 66(12): 27632766.

19. Abdulla A.A., Hussein O.M. Al-Dahmoshi, Thikra A. Abed. Wurood H. Muttaleb. Characterization of Multidrug Resistant Carbapenemases-Producing Escherichia coli and Klebsiella pneumoniae Isolates from Urinary Tract Infection. J. Chem. Pharm. Scie, 2016; 9(3): 1116-1120.

20. Zowawi H.M., Anna L. Sartor, Hanan H. Balkhy, Timothy R. Walsh, Sameera M.A.I. Johani, Reem Y. AlJindan. Molecular characterization of carbapenemaseproducing Escherichia coli and Klebsiella pneumoniae in the countries of the Gulf cooperation council: dominance of OXA-48 and NDM producers. Antimicrob Agents Chemother, 2014; 58: 3085-90.

21. Moubareck C.A., Shaimaa F. Mouftah, Tibor P., Akela G., Dalal H. Halat, Anju N., Mouza A. AlSharhan, etal. Clonal emergence of Klebsiella pneumoniae ST14 coproducing OXA-48-type and NDM carbapenemases with high rate of colistin resistance in Dubai, United Arab Emirates. Intern. J. Anti. microb. Agents, 2018; 52(1): 1-6.

22. Dandachi I, SalemESokhn,ElieN, EidA.ZiadD. Carriage of beta-lactamase-producing Enterobacteriaceae among nursing home residents in north Lebanon. Intern. J. Infect. Dis, 2016; 45: 24-31.

23. Mohamed S.R., Alfadil A., Wafa MHussien, Mohamed I. 
Saeed. blaOXA-48Carbapenem Resistant Pseudomonas aeruginosa Clinical Isolates in Sudan. J. Adv. Microbiol., 2018; 10(4): 1-5.

24. Dortet L., Gaelle C., Patrice N. Dissemination of carbapenemase-producing Enterobacteriaceae in France, 2012. J. Anti. microb. Chemother, 2013; 69(3): 623-627.

25. Dortet L., Mirela Fl, Yves-Marie $\mathrm{Bl}$, Elodie $\mathrm{Cl}$, Sandrine BI, Anals VI, Thierry N. Dissemination of carbapenemase-producing Enterobacteriaceae and Pseudomonas aeruginosa in Romania. Anti. microb. Agents Chemother., 2015; 59(11): 7100-7103.

26. Mataseje L.F., David A. Boyd, Jeffrey F., David H., Linda $\mathrm{H}$., et al. Characterization of OXA-48-like carbapenemase producers in Canada, 2011-14. J. Antimicrob. Chemother, 2017; 73(3):626-633.

27. AL_Jubori S.S., Israa M. AL_Kadmy, Zuhar J. Al_ Ani. Emergence of multidrug resistance (MDR) Acinetobacter baumannii isolated from Iraqi hospitals. Adv. Environ. Biol., 2016; 10(5):265-276.

28. Hammadi A.H., Najlaa N. Yaseen, Harith JF AlMathkhury. Molecular Detection of Some $\beta$-lactamases Genes in Uropathogenic Escherichia coli. Iraqi J.Sci., 2015; 56(3A): 1925-1931.

29. Djahmi N., Catherine D.-R.,AlixP, Mazouz D., Albert S., Jean-Philippe L. Epidemiology of carbapenemaseproducing Enterobacteriaceae and Acinetobacter baumannii in Mediterranean countries. Bio. Med. res. int., 2014. http://dx.doi.org/10.1155/2014/305784.

30. Guerin F., Corneliu H., Gabriella S., Odile L., Dominique S.-C., Claire. Bacterial prostatitis due to Pseudomonas aeruginosa harbouring the blaVIM-2 metallo- $\beta$ lactamase gene from Saudi Arabia. J. Antimicrob. Chemother, 2005; 56(3): 601-602.

31. Rajabnia R., Fariba A., Elaheh Ferdosi Shahandashti, Zahra M. Nosocomial emerging of (VIM1) carbapenemase-producing isolates of Klebsiella pneumoniae in North of Iran. Iran J. Microbiol., 2015; 7(2): 88-93.

32. Haciseyitoglu D., Aysegul D., Ayham A., Fatma E., Yasemin C., Serdar O., Zerrin A. The First Enterobactercloacae Co-Producing NDM and OXA-48 Carbapenemases and Interhospital Spread of OXA48 and NDM-Producing Klebsiell-apneumoniae in Turkey. Clin. Lab. , 2017; 63(7): 1213-1222.

33. Hammami S., Boutiba-Ben B.R.Ghozzi, M. Saidani, S. Amine, S. Ben Redjeb. Nosocomial outbreak of imipenem-resistant Pseudomonasaeruginosa producing VIM-2 metallo- $\beta$-lactamase in a kidney transplantation unit. Diag. pathol, 2011; 6(1): 106.

34. Mereưt Al, Aida CBTdescu, Olivia S. Dorneanu, Luminía Slancu, Cristina GTuchilus. Spread of VIM-2 metallobeta-lactamase in Pseudomonas aeruginosa and Acinetobacter baumannii clinical isolates from lasi, Romania. Rom Rev. Lab. Med., 2013; 21(4): 423-430.

35. Hong JS, Eun-Jeong Y, WonkeunS, Yu BSeo,SaeamS, Min-Jeong P, Seok HJeong, KyungwonL. Molecular Characterization of Pseudomonas putida Group Isolates Carrying blaVIM-2 Disseminated in a University Hospital in Korea. Microbial Drug Resist,2018; 24(5): 627-634.

36. Touati M., Seydina M. Diene, Mazouz D., Abdelghani
D., Abdelkarim R., Jean-Marc R. Dissemination of class I integron carrying VIM-2 carbapenemase gene in Pseudomonasaeruginosa clinical isolates from intensive care unit of university hospital of Annaba, Algeria. Antimicrob. Agents and Chemother., 2013; 57(5): 2426-2427.

37. Kazi M., Drego L., Chaitali N., Kanchan A., Rajeev S., Anjali S., C. Rodrigues. Molecular characterization of carbapenem-resistant Enterobacteriaceae at a tertiary care laboratory in Mumbai. Eur. J. Clin. Microbiol. Infect. Dis., 2015; 34(3): 467-472.

38. Alshara J.M.R., Zuhair S.R. Alsehlawi, Dheyaa S.A. Aljameel, Zeena S. Al-Zubbedy, Ali MAlmohana. First report of New Delhi metallo-beta-lactamase (NDM-1) producing Pseudomonas aeruginosa in Iraq. J. Biol. Agricul. Healthcare, 2014; 4: 40-7.

39. Al-Harmoosh R.A., Eman M. Jarallah. First Detection of the blaNDM-1 and blaNDM-2 Genes IN a Clinical Isolates of Acinetobacter baumannii in Hillah HospitalsIraq. Int. J. Adv. Res., 2015; 3(10): 1407-1416.

40. Hussein N.H. Genotypic Detection of CarbapenemResistant Escherichia coli Producing NDM-1 Gene for the First Time in Baghdad/Iraq. J. Glob. Pharma. Tech., 2017; 09(9): 106-111.

41. Hammoudi A.A., Azhar N. Hussein, Mohammed S. Jebur. Detection of blaNDM -Metallo- $\beta$-Lactamase Genes in Klebsiella pneumoniae Strains Isolated From Burn Patients in Baghdad Hospitals. Med.J. Babylon, 2016; 13( 4): $904-913$.

42. Nordmann P., Laurent D., Laurent P. Carbapenem resistance in Enterobacteriaceae: here is the storm!. Trends Mol. Med.,2012; 18(5): 263-272.

43. Sonnevend :, Akela A. Ghazawi, Rayhan H., Wafaa J., Vincent $O$. Rotimi, Atef M. Shibl, Amina A., et al. Characterization of carbapenem-resistant Enterobacteriaceae with high rate of auto-chthonous transmission in the Arabian Peninsula. PLoS One, 2015; 10(6): e0131372.

44. Ben Helal R., Raoudha D., Meriem C., Naouel K., Farouk B., Mohamed S. El Asli, Mohamed B. Moussa. Occurrence and Characterization of CarbapenemaseProducing Enterobacteriaceae in a Tunisian Hospital. Microb. Drug Resist., 2018; 24(9): https:// doi.org/10.1089/mdr.2018.0013

45. Khatun R., Shamsuzzaman S.M. Detection of OXA181/OXA-48 carbapenemase producing Enterobacteriaceae in Bangladesh. Ibrahim Med. Coll. J., 2015; 9(2): 45-51.

46- $\quad$ Ageevets VA, Irina VPartina, Eugenia SLisitsyna, Elena NIlina, Yuri VLobzin, Sergei A. Shlyapnikov, Sergei VSidorenko. Emergence of carbapenemase -producing Gram-negative bacteria in Saint Petersburg, Russia. Int. J. Antimicrob. Agents., 2014; 44(2): 152-155.

47. Meletis G.,Dimitrios C., Nikos M. Double-and multicarbapenemase-producers: the excessively armored bacilli of the current decade. Eur. J. Clin. Microbiol. Infect. Dis., 2015; 34(8): 1487-1493

48. Jamal W.Y., M.J. Albert, Vincent O. Rotimi. High prevalence of new delhimetallo- $\beta$-lactamase- 1 (NDM-1) producers among carbapenem-resistant Enterobacteriaceae in Kuwait. PloS one, 2016; 11(3), https://doi.org/10.1371/journal. pone.0152638. 
49. Doi Y., Jessica A. O'Hara, James F. Lando, Ashley M. Querry, Bethany M. Townsend, Anthony W. Pasculle, Carlene A. Muto. Co-Production of NDM-1 and OXA232 by Klebsiella pneumoniae. Emerg. Infect. Dis., 2014; 20(1): 164-165.

50. Bousquet, Aurore, Marion Duprilot, Didier Moissenet, B'atriceSalauze, J'romeRambaud, etal. "First case of multidrug-resistant blaNDM-1-and blaOXA-232- carrying Klebsiella pneumoniae and its probable crosstransmission in a French hospital." Int. J. Antimicrob. Agents, 2014; 44( 5): 469-470.

51. Lin K.Y., Tsai-Ling L., Jann-Tay W., Shan-Chwen C.Carbapenem-resistant Pseudomonas aeruginosa in Taiwan: Prevalence, risk factors, and impact on outcome of infections. J. Microbiol. Immun. Infect., 2016; 49(1):52-59. 